\title{
Effects of E407a on the viability, metabolic and functional activity of dermal fibroblasts
}

\author{
Anton Tkachenko ${ }^{1,2}$, Volodymyr Prokopiuk ${ }^{1,3}$, Anatolii Onishchenko ${ }^{1,2}$, Maria Shevchenko ${ }^{3}$ \\ ${ }^{1}$ Research Institute of Experimental and Clinical Medicine, Kharkiv National Medical University, Kharkiv, Ukraine \\ ${ }^{2}$ Department of Biochemistry, Kharkiv National Medical University, Kharkiv, Ukraine \\ ${ }^{3}$ Department of Cryobiology of the Reproduction System, Institute for Problems of Cryobiology and Cryomedicine of the National Academy of Sciences \\ of Ukraine, Kharkiv, Ukraine
}

Received: 2021-06-29.

Accepted: 2021-08-25

This work is licensed under a Creative Commons Attribution 4.0 International License

J Clin Med Kaz 2021; 18(5):49-53

Corresponding author:

Anton Tkachenko.

E-mail: as.tkachenko@knmu.edu.ua;

ORCID: 0000-0002-1029-1636

\section{Abstract}

Aim: To evaluate the effects of semi-refined carrageenan (E407a) on the viability, metabolic and functional activity of skin fibroblasts in vitro.

Material and methods: Various concentrations of E407a $10-10$ mg/ $\mathrm{ml}$ ) were incubated for $24 \mathrm{~h}$ with skin fibroblast cultures isolated from rat embryos. The viability of cells exposed to semi-refined carrageenan was assessed by the neutral red uptake assay. MTT test was selected to estimate the metabolic activity of cells. In addition, scratch assay was used to determine the functional activity of dermal fibroblasts.

Results: Direct exposure to semi-refined carrageenan did not affect the viability of rat dermal fibroblasts, evidenced by the results of MTT and neutral red uptake assays. However, experimental data of MTT and scratch assays revealed that high concentrations of this food additive increased the metabolic activity of fibroblasts and diminished the motility of these cells, suggesting that E407a is cytotoxic at high concentrations.

Conclusion: Food-grade semi-refined carrageenan is cytotoxic towards skin fibroblasts at high concentrations.

Key words: neutral red uptake assay, MTT assay, scratch assay, carrageenan

\section{Introduction}

Food additives are either naturally occurring or artificial compounds whose purpose is to improve the texture of foods, increase their shelf-life and improve their organoleptic properties. International regulatory authorities such as the U.S.-based Food and Drug Administration (FDA) and European Food Safety Authority (EFSA) have initiated the thoughtful reevaluation of food additives to guarantee their safety for consumers. Among the food additives whose safety is debated, carrageenans seem to be the most controversial [1-5]. Carrageenans are phycocolloids of heteropolysaccharide origin commercially produced from red algae and widely represented in human diet. Cost-effectiveness and convenience of their application in technological processes make them indispensable in the production of processed and ultraprocessed food. The content of carrageenans, which are registered as native carrageenan (E407) and semi-refined form (E407a) can vary to a high extent and may reach $0.5-1 \%$ of weight for some dairy products, processed meat and fruit-based processed foods [5].
Carrageenans are flexible molecules with the helical structure extracted primarily from red algae of the genus Eucheuma and composed of alternating 1,3-linked D-galactopyranosyl and 1,4-linked D-galactopyranosyl units [6]. There are three basic forms of carrageenan: kappa, iota, and lambda, which differ in their structural properties, sulfation degree, and technological characteristics in the food industry. Nowadays all major forms of carrageenans are recognized as safe for consumption by humans. However, their safety has been challenged by multiple experimental animal studies, culture-based experiments and even some clinical trials [1, 7-13]. Of note, several mechanisms have been suggested to be implicated in carrageenan-mediated gut toxicity. For instance, carrageenan has been shown to inhibit gastric and intestinal proteases such as pepsin and trypsin, reducing in this manner dietary protein bioavailability [5]. Moreover, this food additive has been demonstrated to increase the intestinal permeability, compromising the barrier function [5]. This becomes critical in case of the compromised mucus layer, which can cause direct exposure of intestinal lining to carrageenans. 
Furthermore, several recently published papers emphasize the ability of carrageenans to aggravate intestinal inflammation by modulating the gut microbiota [14-16]. Carrageenans have been reported to impair glucose metabolism, contributing to insulin resistance [17, 18]. Despite numerous and diverse data on the effects of orally ingested carrageenans, cell cultures provide controversial conclusions concerning the safety profile of E407a $[1,8,19,20]$. This suggests that more cell culture-based experiments are required to analyze the impact of carrageenans on cells. In particular, scarce information on the effects of carrageenans on fibroblasts is available.

The aim of this research was to analyze the impact of E407a on the viability, metabolic activity and motility of skin fibroblasts to assess its cytotoxicity.

\section{Material and methods Fibroblast cultures}

Fibroblasts were isolated from skin of rat embryos using the enzymatic tissue dissociation procedure [21]. Briefly, skin was separated, fragmented and incubated with $0.25 \%$ trypsinEDTA (BioWest, France) during $1 \mathrm{~h}$ at $37^{\circ} \mathrm{C}$ using a magnetic stirrer. Thereafter, trypsin was inactivated by $10 \%$ fetal bovine serum (FBS, Lonza, Germany) via cell filters with a $100 \mu \mathrm{m}$ pore size. Cells were washed in DMEM (BioWest, France) enriched with $10 \%$ FBS. The fibroblasts were seeded in $25 \mathrm{~cm} 2$ culture flasks (SPL, Republic of Korea). As soon as the 100\% confluence was achieved, the fibroblasts were harvested using $0.25 \%$ trypsin-EDTA and passaged at a ratio of $1: 2$. The cells were used at passages 3-4.

The European Convention for the Protection of Vertebrate Animals used for Experimental and other Scientific Purposes (EST 123), Directive 2010/63/EU for the Protection of Animals Used for Scientific Purposes, and Recommendation 2007/526/ EC were followed. The study was approved by the Commission on Ethics and Bioethics (Kharkiv National Medical University, Kharkiv, Ukraine; minutes \#5 d.d. September 17, 2019).

\section{Neutral red uptake assay}

The neutral red uptake assay was used to evaluate the viability of cells exposed to the food additive E407a [22]. The fibroblasts were seeded in 96-well plates (SPL, Republic of Korea). The amount of cells per well was $1 \times 104$. We used the concentrations of E407a, as well as negative and positive controls, similar to those described above. After incubation of samples for $24 \mathrm{~h}$ in a $\mathrm{CO}_{2}$-incubator $\left(5 \% \mathrm{CO}_{2}\right), 0.1 \mathrm{ml}$ culture medium was incubated with a neutral red dye at a final concentration of $0.003 \%$ during $3 \mathrm{~h}$ in a $\mathrm{CO}_{2}$-incubator $(5 \%$ $\left.\mathrm{CO}_{2}\right)$. Then the medium was collected and $0.1 \mathrm{ml}$ of $50 \%$ ethanol and $3 \%$ acetic acid were added to extract and dissolve the neutral red dye. Absorbance was determined at $570 \mathrm{~nm}$. Numerical values are expressed in optical density (OD) units.

\section{MTT assay}

To analyze the metabolic activity of cells treated with E407a, fibroblasts were seeded into 96-well plates (SPL, Republic of Korea) at a concentration of $1 \times 104$ per well. The experiment was performed the next day after seeding, adhesion and formation of fibroblast monolayers.

The cells were incubated with E407a for $24 \mathrm{~h}$ in a $\mathrm{CO}_{2}$ incubator (Thermo Fisher Scientific, USA) at the concentrations of $10,25,50,100,200,500,1000,5000,10000 \mu \mathrm{g} / \mathrm{ml}(\mathrm{n}=8$ in each group of samples, $37^{\circ} \mathrm{C}, 5 \% \mathrm{CO}_{2}$ ). The negative and positive controls included the cells incubated with no carrageenan and fibroblasts killed by $70 \%$ ethanol, respectively. Then the medium was discarded and $0.1 \mathrm{ml}$ culture medium with $15 \mu \mathrm{l}$ MTT at a concentration of $5 \mathrm{mg} / \mathrm{ml}$ was added. Incubation in a $\mathrm{CO}^{2}$-incubator lasted for $3 \mathrm{~h}$ at $37^{\circ} \mathrm{C}$ and $5 \% \mathrm{CO}_{2}$. Thereafter, the medium was collected and $0.1 \mathrm{ml}$ dimethyl sulfoxide with sodium dodecyl sulfate was added to dissolve formazan. This was followed by incubation for $1 \mathrm{~h}$ at $37^{\circ} \mathrm{C}$. Absorbance was measured at $570 \mathrm{~nm}$. Numerical values are expressed in optical density (OD) units.

\section{Scratch assay}

To assess the alterations of mobility and proliferation under the influence of E407a, the scratch assay was carried out [23]. The next day after seeding fibroblasts in 24-well plates at a concentration of $1 \times 10^{5}$ per well, a dispensable pipette was used to make a scratch in a $100 \%$ confluent cell monolayer. The cells were incubated with E407a using the concentrations and conditions outlined above. The width of the damaged area was measured directly after making the defect, as well as after 24 and $48 \mathrm{~h}$, respectively. The width of cell-free areas was determined in three regions (top, middle, and bottom) of each well.

To visualize data, a Delta Optical NIB 100 inverted microscope (Poland) and Sigeta MCMOS 3100 3.1MP camera (China) were used. Images were processed using ToupView V 3.7 software (Hangzhou Toup Tek Photonics Co. Ltd, Hangzhou, China).

\section{Statistical analysis}

The distribution normality was assessed by the ShapiroWilk test. The non-parametric Kruskal-Wallis followed by the Dunn's test was used to detect the statistically significant differences between several independent groups of variables. Data are demonstrated as the median $(\mathrm{Me})$ and interquartile range (IQR; 25\%-75\%). A value of p below 0.05 indicated the statistically significant difference. Graph Pad Prism 5.0 application was used to perform the statistical analyses.

\section{Results}

Visually, no noticeable changes in the fibroblast monolayers were observed compared with the control samples if smaller concentrations of E407a, i.e. below $5 \mathrm{mg}$ per $\mathrm{ml}$, were used. The cells were characterized by a prolonged shape. They were tightly attached to each other. The monolayer was $100 \%$ confluent. When higher concentrations were applied, i.e. $5 \mathrm{mg} /$ $\mathrm{ml}$ and over, the fibroblasts partially lost adhesive properties, became polygonal and the confluence was approximately 40$50 \%$. However, the complete loss of adhesion was not detected (Figure 1). It is worth noting that the changes were reversible. The next day after the removal of E407a, the monolayer structure returned.

Figure 1 - Cultured fibroblast monolayers treated with various concentrations of the food additive E407a (A - $0 \mu \mathrm{g} / \mathrm{ml}$; B - 100 $\mathrm{\mu g} / \mathrm{ml}$; C - $5 \mathrm{mg} / \mathrm{ml}$ ) during $24 \mathrm{~h}$. Phase contrast microscopy. The scale bar is $100 \mu \mathrm{m}$.

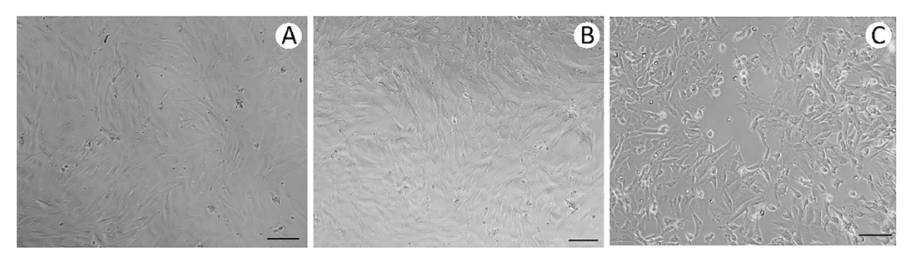


Figure $\mathbf{2}$ - Representative images of cultured dermal fibroblasts exposed to different concentrations of the food additive E407a (A - $0 \mu \mathrm{g} / \mathrm{ml}$; B - $100 \mu \mathrm{g} / \mathrm{ml}$; C - $5 \mathrm{mg} / \mathrm{ml}$ ) for $24 \mathrm{~h}$ and subsequently stained with the neutral red dye. Phase contrast microscopy. The scale bar is $100 \mu \mathrm{m}$.

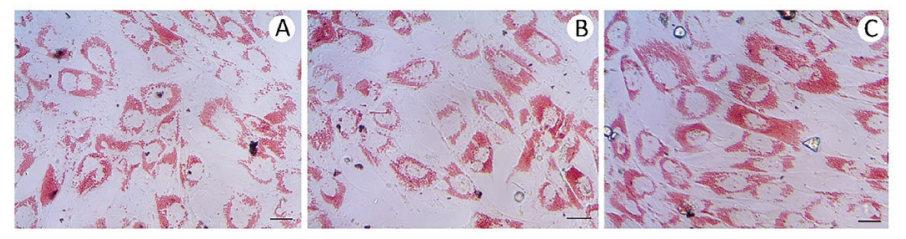

Figure 3 - The viability of fibroblasts exposed to E407a at concentrations 0-10 $\mathrm{mg} / \mathrm{ml}$ for $24 \mathrm{~h}$ was assessed by neutral red uptake assay. Numerical data are presented in optical density (OD) units. The food additive E407a was not found to affect cell viability.

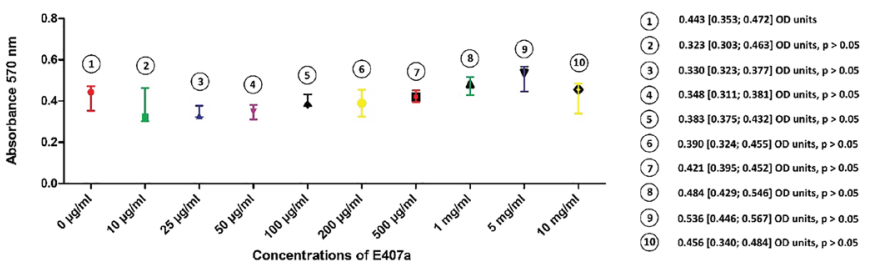

Figure 4 - The metabolic activity of dermal fibroblasts treated with semi-refined carrageenan (E407a) for $24 a(0-10 \mathrm{mg} / \mathrm{ml}$ of the food additive) was estimated quantitatively using MTT assay. Numerical values are expressed in optical density (OD) units. Exposure to E407a at a concentration of $5 \mathrm{mg} / \mathrm{ml}$ and higher statistically significantly increased the metabolic activity of fibroblasts compared with control samples.
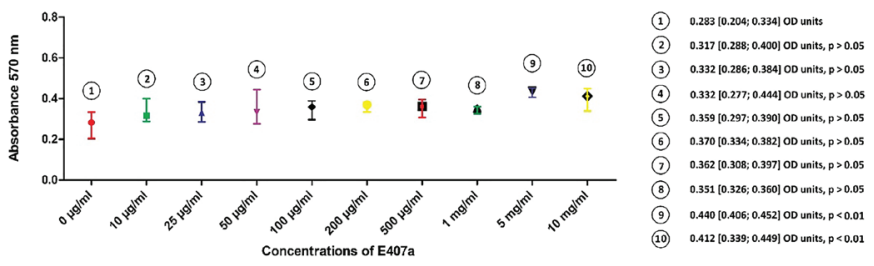

A complex evaluation of E407a cytotoxicity towards rat skin fibroblasts was performed. Data of MTT test and neutral red uptake assay showed that carrageenan had no effect on cell viability, which was confirmed by the absence of statistically significant $(p>0.05)$ reduction of optical density values in fibroblast suspensions treated with carrageenan and subsequently stained with vital dyes: MTT and neutral red (Figures 2-4). On the contrary, the statistically significant $(p<0.01)$ elevation of optical density values in samples incubated with $5 \mathrm{mg} / \mathrm{ml}$ and $10 \mathrm{mg} / \mathrm{ml}$ of E407a for $24 \mathrm{~h}$ while carrying out the MTT assay suggested that E407a increased the metabolic activity of cells. The increase in the parameter studied was 1.6- and 1.5-fold, respectively (Figure 4).

The same trend was observed in case of the functional scratch assay. Concentrations of semi-refined carrageenan below $1 \mathrm{mg} / \mathrm{ml}$ did not have any impact on the motility of fibroblasts, evidenced by no statistically significant changes $(p>0.05)$ in the width of cell-uncovered regions within $48 \mathrm{~h}$ after the assay performance (Figure 5). However, after $48 \mathrm{~h}$ almost a 3 -fold reduction in the size of cell-free areas was revealed in the samples exposed to high concentrations of E407a (over $1 \mathrm{mg} /$ $\mathrm{ml})$.
Figure 5 - Scratch assay was used to assess the motility of fibroblasts after exposure to semi-refined carrageenan (E407a) for $24 \mathrm{a}$ at the concentrations of $0-10 \mathrm{mg} / \mathrm{ml}$. The width of cellfree areas was compared followed a formation of scratches by a pipette time after 0, 24 and 48 h, respectively. Semi-refined carrageenan at concentrations of $1 \mathrm{mg} / \mathrm{ml}$ and above statistically significantly reduced the motility of fibroblasts compared with controls.
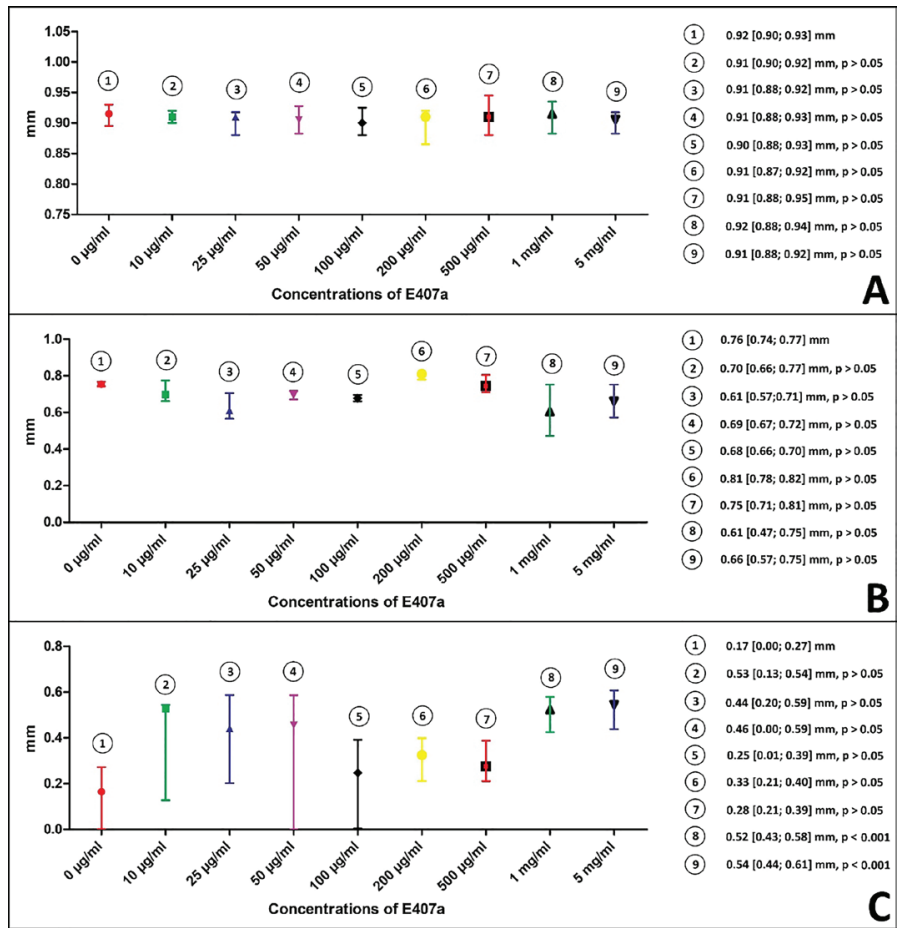

(1) $0.17[0.00 ; 0.27] \mathrm{mm}$

(2) $0.53[0.13 ; 0.54] \mathrm{mm}, \mathrm{p}>0.05$

(3) $0.44[0.20 ; 0.59] \mathrm{mm}, \mathrm{p}>0.05$

(4) $0.46[0.00 ; 0.59] \mathrm{mm}, p>0.05$

(5) $0.25[0.01 ; 0.39] \mathrm{mm}, \mathrm{p}>0.05$ (6) $0.33[0.22 ; 0.40] \mathrm{mm}, p>0.05$ (7) $0.28[0.21 ; 0.39] \mathrm{mm}, p>0.05$ (8) $0.52[0.43 ; 0.58] \mathrm{mm}, 0<0.001$ (9) $0.54[0.040 .061] \mathrm{mm}, \mathrm{p}<0.000$ (9) $0.54[0.44 ; 0.61] \mathrm{mm}, \mathrm{p}<0.00$

\section{Discussion}

The complex assessment of semi-refined carrageenan cytotoxicity to skin fibroblasts performed in this study shows that partial toxic effects are typical only for high concentrations of this food additive. Our experimental data prove that the concentrations exceeding $5 \mathrm{mg} / \mathrm{ml}$ increase the metabolic activity of cells against the background of the reduction of functional activity, i.e. motility of fibroblasts. A higher metabolic activity of fibroblasts induced by exposure to high concentrations of E407a may indicate the compensatory mitochondrial hyperactivation as a part of the stress-induced response. Since MTT is converted to formazan in mitochondria, our findings suggest that the carrageenan toxicity is at least partially associated with mitochondria-mediated mechanisms. There is some evidence that such changes in the results of MTT viability assays may be due to either mitochondrial biogenesis, which can compensate for the damage to mitochondria caused by E407a, or even a higher generation of formazan by the reduced number of overactivated surviving cells [24].

Our data are consistent with other findings, in particular, the inability of different types of undegraded carrageenan to promote cell death in human intestinal and hepatic cells [19, 20]. Degraded carrageenan, whose toxicity is compellingly demonstrated, induced apoptosis and blocked cell proliferation in normal and cancer intestinal and hepatic cell lines [19].

It is important to mention that immune cells are more sensitive to carrageenan cytotoxic effects. Our earlier studies demonstrate the uptake of semi-refined carrageenan by leukocytes and anti-apoptotic bcl-2 upregulation in lymphocytes in vitro, as well as excessive ROS production and activated apoptosis of circulating leukocytes after E407a ingestion in 
vivo [25, 26]. Moreover, semi-refined carrageenan increases the metabolic activity of splenocytes and bone marrow cells at lower concentrations compared with fibroblasts (unpublished data). This observation is of huge importance due to the presence of experimental evidence on the inability of carrageenans to be absorbed and their interaction with host intestinal immune cells $[4,20,27]$. In particular, there is some evidence that highmolecular-weight carrageenan can overcome the intestinal barrier via macrophages in Peyer's patches [28].

It has been reported that carrageenan toxicity is mediated by the TLR4-and NF-kB-associated pathways, NLRP3 inflammasome pathway, ROS-mediated damage and, hence, upregulation of pro-inflammatory cytokines [25, 29-31]. The role of pathways outlined above in immune cells is more pronounced compared with fibroblasts, which can be speculated to explain the difference in cytotoxic effects of semi-refined carrageenan on different types of cells. However, more cell culture-based and animal studies should be carried out to elucidate molecular mechanisms by which carrageenans exert their pro-inflammatory activities.

\section{Conclusion}

Semi-refined carrageenan (E407a) shows cytotoxic properties to skin fibroblast cell cultures at high concentrations.

Disclosures: There is no conflict of interest for all authors.

Acknowledgements: The authors express sincere gratitude to all those who contributed to this research in any way.

The study was performed as a fragment of the research entitled "Biochemical Mechanisms for the Induction of Intestinal Inflammation and the Ways of its Correction (Kharkiv National Medical University, Kharkiv, Ukraine; state registration number 0120U102645).

\section{Funding: None.}

\section{References}

1. Tobacman JK. Review of harmful gastrointestinal effects of carrageenan in animal experiments. Environ Health Perspect. 2001; 109(10):983-94. doi: 10.1289/ehp.01109983.

2. Bixler HJ. The carrageenan controversy. J Appl Phycol. 2017; 29:2201-2207. https://doi.org/10.1007/s10811-017-1132-4

3. David S, Shani Levi C, Fahoum L, Ungar Y, Meyron-Holtz EG, Shpigelman A, et al. Revisiting the carrageenan controversy: do we really understand the digestive fate and safety of carrageenan in our foods? Food Funct. 2018; 9(3):1344-1352. doi: 10.1039/c7fo01721a.

4. Younes M, Aggett P, Aguilar F, Crebelli R, Filipič M, Frutos MJ, et la. Re-evaluation of carrageenan (E 407) and processed Eucheuma seaweed (E 407a) as food additives. EFSA J. 2018; 16(4):e05238. doi: 10.2903/j.efsa.2018.5238.

5. Liu F, Hou P, Zhang H, Tang Q, Xue C, Li RW. Food-grade carrageenans and their implications in health anddisease. Compr Rev Food Sci Food Saf. 2021; 1-19. https://doi.org/10.1111/1541-4337.12790

6. Stanley N (2011). FAO Corporate document repository. Chapter 3: Production, properties and uses of carrageenan. FMC Corporation, Marine Colloids Division 5 Maple Street, Rockland Maine 04841, USA

7. Cohen SM, Ito N. A critical review of the toxicological effects of carrageenan and processed eucheuma seaweed on the gastrointestinal tract. Crit Rev Toxicol. 2002; 32(5):413-44. doi: 10.1080/20024091064282.

8. Necas J, Bartosikova L. Carrageenan: a review. Veterinarni Medicina. 2013; 58:187-205.

9. Gubina-Vakyulyk GI, Gorbach TV, Tkachenko AS, Tkachenko MO. Damage and regeneration of small intestinal enterocytes under the influence of carrageenan induces chronic enteritis. Comparative Clinical Pathology. 2015; 24(6):1473-1477. https://doi.org/10.1007/ s00580-015-2102-3

10. Bhattacharyya S, Shumard T, Xie H, Dodda A, Varady KA, Feferman L, et al. A randomized trial of the effects of the no-carrageenan diet on ulcerative colitis disease activity. Nutr Healthy Aging. 2017; 4(2):181-192. doi: 10.3233/NHA-170023.

11. Martino JV, Van Limbergen J, Cahill LE. The role of carrageenan and carboxymethylcellulose in the development of intestinal inflammation. Front Pediatr. 2017; 5:96. doi:10.3389/fped.2017.00096

12. Tkachenko A, Marakushyn D, Kalashnyk I, Korniyenko Y, Onishchenko A, Gorbach T, et al. A study of enterocyte membranes during activation of apoptotic processes in chronic carrageenan-induced gastroenterocolitis. Med Glas (Zenica). 2018; 15(2):87-92. doi: 10.17392/946-18.

13. Tkachenko A, Onishchenko A, Roshal A, Nakonechna O, Chumachenko T, Posokhov Y. Effects of semi-refined carrageenan (food additive E407a) on cell membranes of leukocytes assessed in vivo and in vitro. Med Glas (Zenica). 2021; 18(1). doi: 10.17392/1213-21.

14. Shang Q, Sun W, Shan X, Jiang H, Cai C, Hao J, et al. Carrageenan-induced colitis is associated with decreased population of antiinflammatory bacterium, Akkermansia muciniphila, in the gut microbiota of C57BL/6J mice. Toxicol Lett. 2017; 279:87-95. doi: 10.1016/j.toxlet.2017.07.904.

15. Wu W, Zhen Z, Niu T, Zhu X, Gao Y, Yan J, et al. $\kappa$-Carrageenan Enhances Lipopolysaccharide-Induced Interleukin-8 Secretion by Stimulating the Bcl10-NF-kB Pathway in HT-29 Cells and Aggravates C. freundii-Induced Inflammation in Mice. Mediators Inflamm. 2017; 2017:8634865. doi: 10.1155/2017/8634865.

16. Mi Y, Chin YX, Cao WX, Chang YG, Lim PE, Xue CH, et al. Native $\kappa$-carrageenan induced-colitis is related to host intestinal microecology. Int J Biol Macromol. 2020; 147:284-294. doi: 10.1016/j.jibiomac.2020.01.072.

17. Bhattacharyya S, Feferman L, Unterman T, Tobacman JK. Exposure to common food additive carrageenan alone leads to fasting hyperglycemia and in combination with high fat diet exacerbates glucose intolerance and hyperlipidemia without effect on weight. $J$ Diabetes Res. 2015; 2015:513429. doi:10.1155/2015/513429

18. Bhattacharyya S, O-Sullivan I, Katyal S, Unterman T, Tobacman JK. Exposure to the common food additive carrageenan leads to glucose intolerance, insulin resistance and inhibition of insulin signalling in HepG2 cells and C57BL/6J mice. Diabetologia. 2012; 55(1):194-203. doi: 10.1007/s00125-011-2333-z. 
19. Ariffin SH, Yeen WW, Abidin IZ, Abdul Wahab RM, Ariffin ZZ, Senafi S. Cytotoxicity effect of degraded and undegraded kappa and iota carrageenan in human intestine and liver cell lines. BMC Complement Altern Med. 2014; 14:508. doi:10.1186/1472-6882-14-508

20. McKim JM Jr, Baas H, Rice GP, Willoughby JA Sr, Weiner ML, Blakemore W. Effects of carrageenan on cell permeability, cytotoxicity, and cytokine gene expression in human intestinal and hepatic cell lines. Food Chem Toxicol. 2016; 96:1-10. doi: 10.1016/j.fct.2016.07.006.

21. Chang Y, Guo K, Li Q, Li C, Guo Z, Li H. Multiple directional differentiation difference of neonatal rat fibroblasts from six organs. Cell Physiol Biochem. 2016; 39(1):157-71. doi: 10.1159/000445613.

22. Repetto G, del Peso A, Zurita JL. Neutral red uptake assay for the estimation of cell viability/cytotoxicity. Nat Protoc. 2008; 3(7):112531. doi: 10.1038/nprot.2008.75.

23. Hulkower KI, Herber RL. Cell migration and invasion assays as tools for drug discovery. Pharmaceutics. 2011; 3(1):107-24. doi: 10.3390/pharmaceutics3010107

24. Rai Y, Pathak R, Kumari N, Sah DK, Pandey S, Kalra N, et al. Mitochondrial biogenesis and metabolic hyperactivation limits the application of MTT assay in the estimation of radiation induced growth inhibition. Sci Rep. 2018; 8(1):1531. doi: 10.1038/s41598-01819930-w.

25. Tkachenko AS, Kot YG, Kapustnik VA, Myasoedov VV, Makieieva NI, Chumachenko TO, et al. Semi-refined carrageenan promotes reactive oxygen species (ROS) generation in leukocytes of rats upon oral exposure but not in vitro. 2021; 171(3-4):68-78. doi: 10.1007/ s10354-020-00786-7.

26. Tkachenko AS, Onishchenko AI, Lesovoy VN, Myasoedov VV. Common food additive E407a affects BCL-2 expression in lymphocytes in vitro. Studia Univ. VG, SSV, 2019; 29(4):169-76.

27. McKim JM, Willoughby JA Sr, Blakemore WR, Weiner ML. Clarifying the confusion between poligeenan, degraded carrageenan, and carrageenan: A review of the chemistry, nomenclature, and in vivo toxicology by the oral route. Crit Rev Food Sci Nutr. 2019; 59(19):3054-3073. doi: 10.1080/10408398.2018.1481822.

28. Nicklin S, Miller K. Effect of orally administered food-grade carrageenans on antibody-mediated and cell-mediated immunity in the inbred rat. Food Chem Toxicol. 1984;22(8):615-21.

29. Bhattacharyya S, Dudeja PK, Tobacman JK. Carrageenan-induced NFkappaB activation depends on distinct pathways mediated by reactive oxygen species and Hsp27 or by Bcl10. Biochim Biophys Acta. 2008; 1780(7-8):973-982. doi:10.1016/j.bbagen.2008.03.019

30. Barth CR, Funchal GA, Luft C, de Oliveira JR, Porto BN, Donadio MV. Carrageenan-induced inflammation promotes ROS generation and neutrophil extracellular trap formation in a mouse model of peritonitis. Eur J Immunol. 2016; 46(4):964-70. doi: 10.1002/ eji.201545520.

31. Lopes AH, Silva RL, Fonseca MD, Gomes FI, Maganin AG, Ribeiro LS, et al. Molecular basis of carrageenan-induced cytokines production in macrophages. Cell Commun Signal. 2020; 18(1):141. doi: 10.1186/s12964-020-00621-x. 